CORRIGENDUM

\title{
A systematic review of the validity and reliability of apathy scales in neurodegenerative conditions - CORRIGENDUM
}

\author{
Ratko Radakovic, Catherine Harley, Sharon Abrahams and John M. Starr
}

doi:10.1017/S1041610214002221. Published online by Cambridge University Press, 30 October 2014.

In the above mentioned article by Radakovic et al., a typological error has been found in the Results section under the subheading 'Systematic review'. At the beginning of the second paragraph, the number ' 166 ' should read ' 116 '.

\section{Reference}

Radakovic, R., Harley, C., Abrahams, S. and Starr, J.M. A systematic review of the validity and reliability of apathy scales in neurodegenerative conditions. International Psychogeriatrics, published online 30 October 2014, doi: $10.1017 /$ S1041610214002221 